\title{
NATURAL LIGHT AS A DETERMINANT OF THE IDENTITY OF ARCHITECTURAL SPACE
}

\author{
Ilker Fatih Ozorhon ${ }^{\mathrm{a}}$, Turkan Ulusu Uraz ${ }^{\mathrm{b}}$ \\ ${ }^{a}$ Department of Architecture, Faculty of Architecture and Design, Ozyegin University, Istanbul, Turkey \\ ${ }^{\mathrm{b} D e p a r t m e n t ~ o f ~ A r c h i t e c t u r e, ~ F a c u l t y ~ o f ~ A r c h i t e c t u r e, ~ E a s t e r n ~ M e d i t e r r a n e a n ~ U n i v e r s i t y, ~ C y p r u s ~}$ \\ E-mail: ailker.ozorhon@ozyegin.edu.tr (corresponding author) \\ Received 26 February 2014; accepted 08 April 2014
}

\begin{abstract}
In this study, the effect of natural light on the architectural space quality was examined. Contribution of natural light in three different dimensions as the readability of the space, the effect of the space, and its aesthetical evaluation was taken into consideration and discussed in the given order. The study involves a review of the related architecture literature, various books, articles, essays, and opinions. The major objective of this research is to explain the place of natural light in architectural design and its different aspects through its functional and semantic dimensions in the space. In this respect, contributions of natural light to the identity of the space were examined based on three renowned Turkish architects and their significant works. The paper focuses on the contribution of natural light to the space, emphasizing its qualitative aspects; whereas its physical and measurable aspects are beyond the scope of the paper. The study demonstrates the importance of experiencing the space in terms of understanding the aspect of light that determines the space identity. It also stresses that buildings designed considering the use of natural light could turn out to be more original.
\end{abstract}

Keywords: natural light, architectural space, semantic dimensions of light, space identity, architectural design.

Reference to this paper should be made as follows: Ozorhon, I. F.; Uraz, T. U. 2014. Natural light as a determinant of the identity of architectural space, Journal of Architecture and Urbanism 38(2): 107-119.

\section{Introduction}

Use of natural light in architectural space can be considered as a significant dimension that has been an element in architectural design ever since the existence of architecture and that has directed it over the course of history. One of the determinants of space is the natural light that sustains it and renders it visible and perceivable. The fact that the relationship between natural light and architecture has both an aesthetical and a functional aspect provided a basis for its development within time.

The functional aspect of natural light defines the most dominant relationship it forms with architecture. Due to this reason, it is possible to state that the first relation between natural lighting and architecture is established through functional - beneficial means (Plummer 2012). Demonstration of architecture through light, definition and perception of volumes, spaces, color, texture and shape features by means of light, and in addition the realization that spatial characteristics and architecture expression can be developed with light has ensured that natural light takes place in architectural design as an aesthetical value.

This dual structure of natural light that compliments each other maintains its presence also today and with the ever advancing technology continues to acquire various dimensions (Dogrusoy 2001).

Besides the functional and thermal advantages of natural light, it also has an aspect that influences the human psychology. Light enables the rhythm of day and night, which affects our lives and in relation our mental status, to be reflected to the space. In addition, natural light is a non-static design element. It constantly changes and moves. Humans need change in their visual environment and daylight is an important 
factor in creating this effect with its variational characteristic. Considering that the colors revealed by natural light provide unlimited diversity even within a day, it is understood that natural light affects the way we understand and perceive the space and that it determines the meaning and character we attach to the space. In this case, it is possible to assert that an incredible level of richness may be generated by using the light within the space.

\section{Light and shade}

Light establishes various relations with the building elements it falls on, via shade that is its opposite, and takes its place in the created visual composition. Shadows appear as a palpable presence and thin or deepen, soften or sharpen according to how they are cast onto walls or settle in space (Plummer 2012). The semantic identity light adopts in this role determines the shape of the elements in space and the qualities of the materials used. Light is an element that completes the design process and that is strongly required to shape the space. The quality and quantity of the light in an architectural space are important factors in an individual's feelings, its behaviors, communication with its environment, and the meaning it attaches to the space. The proper and suitable use of light and shade enhances the effects of aesthetical perception in architecture and evokes various feelings (Altan 1983).

The role of shade in bringing in a plastic value to light is undeniably substantial. Light can only exist as long as it creates shade. Movements on surfaces of objects create different shades. The direction of the light source is as important as its power in the occurrence of shade. As the source of light changes direction, also the shades move and change shape. What enables the color of a surface to have two different tones is the partial shaded or partial lighted status of that surface. In this way, an additional possibility is added to the effect of the structure. Since this new possibility disrupts monotony, it creates a further interesting and plastic appearance.

According to Arnheim (1996), light and shade describe shapes, volumes, spatial positions, textures, depths and many more characteristics. Similarly, Fueg has emphasized the importance of light and shade in architecture as the art of space. He stated that the dimensions of architecture manifest themselves through ratios, play of light, rhythm and colors, and adopted the opinion that architecture is a "plastic occurrence that creates different effects according to light-shade status" (Fueg 1980). Read (1974) particularly mentions the effects of light and shade on the shell of the space.
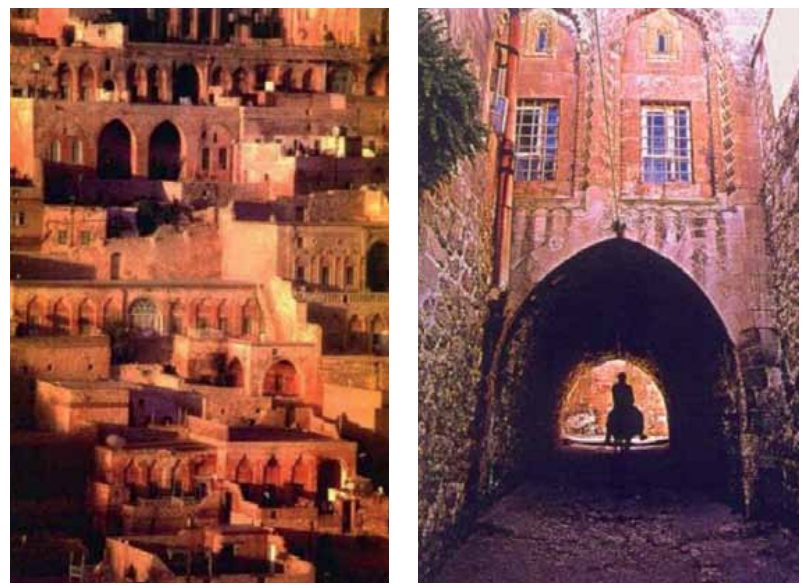

Fig. 1. Mardin

The rhythm of the line, build-up of shapes, space, lightshade and color are the five elements he set forth for analyzing an architectural work. At first, the relation he contemplates between the elements he refers to as the "shape build-up" and light-shade is noteworthy. According to him, light-shade is a consequence of mass-space relationship. In the essence, space is the opposite of the mass of a building. A building is viewed as the space it draws the limits of from interior, and as the mass determined by the surfaces from exterior. In this view, if the interior space is the positive space, then the mass is defined as the negative space (Read 1974).

A different view on light and shade can be in question for urban space or at urban level. When a person is outdoors, he is restricted with buildings and the sky. Mass and surface characteristics of the buildings surrounding the person are defined by light and shade. In cities with stronger urban identity, light is an element that further strengthens this identity. To explain this with an example, speaking of the urban texture of the Turkish city of Mardin might be suitable. Formed by buildings rising on top of each other and by the narrow alleys, one can refer to the city as a "stairs city". Courtyard buildings, the roof of one constituting the terrace of another, embody significant plays of light and shade. While the alleys pass over and below the buildings, light and shade become the expression of these passages. It is possible to state that in the texture of Mardin presented in the figure, light further strengthens this effect (Fig. 1).

\section{Semantic dimension of light in architectural space}

It is possible to assert that the semantic dimension of light springs to life within the semantic relations between light and dark. The quality of being en- 
lightened or dark of spaces stimulates varying semantic effects in the observer. Considering dark physically, it means the case where light does not exist. Regarding dark space, Schulz (1980) goes back in time: "In the past, houses were dark. They resembled caves or the interiors of churches. The light in these spaces was the "dark light" speaking of a divine reality" (Schulz 1980).

Different points of view on dark and light manifest themselves in different cultural occurrences. According to Tanizaki (2001), this difference occurs as follows: He considered what may be the cause of the light - darkness difference that he sees clearly between the Western society and the Eastern society. While a Westerner desires to improve its comfort, a Japanese person gives the greatest priority to keep the values he has in peace. For Westerners it is necessary to have every corner illuminated and have adequate and clean light, while for a Japanese individual, deep shades and a mystical ambiance are more important (Tanizaki 2001).

While perceiving the architectural space consisting of various layers laid on top of each other, the person experiencing the space gravitates towards the space in line with the impressions he gained throughout his life. Light and darkness may bear diverse meanings on the basis of the society, era and culture a person lives in. This is subject to the observer.

According to the differences in the belief systems, the semantic use of natural light varies. "Light is the most effective element in creating the senses of mystery and fear and it is used in religion-related buildings for providing divinity" (Roth 2000). In churches, the symbol of God is expected to create a certain sense of respect integrated with fear in people. The natural light is therefore allowed at a low level into the space. Due to this reason, dimness and a sense of strict discipline are predominant in the architectural spaces of churches. As for an Ottoman mosque, light is adjusted on the basis of the people praying, or in other words, it enters the space at the level of sitting people. In mosques built by the famous architect Sinan and in other Ottoman mosques, light enters the space at the level of people, from above the space and in many cases also from a medium level. The light descending to human level at side spaces surrounding the middle space carries the home environment into the temple. This indicates the nesting of the religious life with the daily life. Use of light in this way originates from the consideration that in Islam, God is everywhere. Accordingly, unlike the churches, in the mosques built by Architect Sinan, light enters the space from everywhere (Fig. 2).
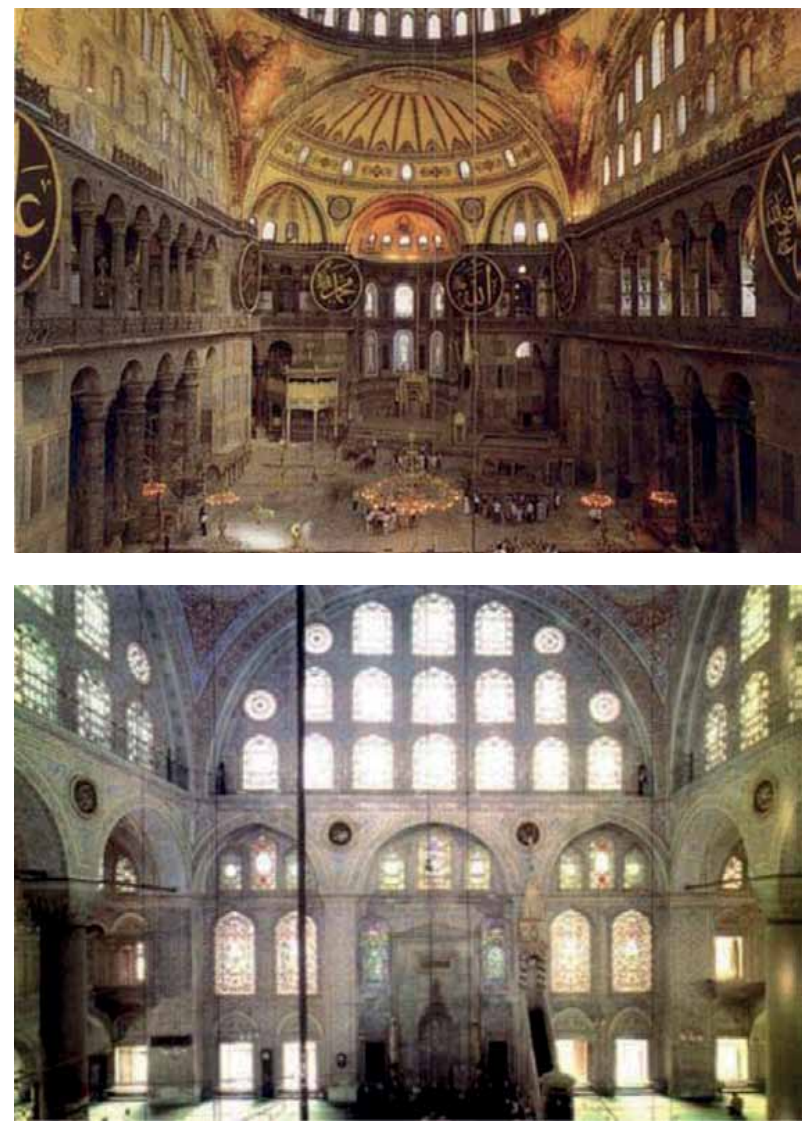

Fig. 2. Hagia Sophia and Mihrimah Sultan Mosque

While the relation of natural light with architectural space and the role it plays in giving the architectural space its shape was examined comprehensively in physical terms. However, the first time it was considered in terms of the aspect that develops the identity of the space took place with Zevi and Giadion's works that came by the late first half of the $20^{\text {th }}$ century. With these works, space has reached a different position in architectural theories and it has drawn the attention of architecture scholars to go beyond the physical and functional use of light. After the 1940s, particularly with the works of Louis I. Kahn on the importance of natural light in architectural space, the identity dimension of light was started to be considered important. Kahn (1968) focused on the identity dimension of natural light and set forward the basic logic of architectural creation with the semantic relationship he established between "light and silence" (Kahn 1968).

Investigating the relationship between space and light in a way to provide hints for designing the space, Rasmussen (1994) states that shifting a window in the middle of a room towards the edge will offer quite different impressions and emphasizes that it is the quality rather than the quality of light that matters. Also Meiss 
(1991) stated that the perception of a space may vary not by changing the quantity of the light it receives but changing its quality. A room receiving daylight from the window presents a different form compared to its form when it is illuminated with artificial light at night time. Alternatively, the height of the dark colored ceiling of a room would be perceived differently in the cases where the room receives light from the side or through daylight. Light gains importance in perceiving the characteristics and textures of the elements surrounding the space and creates plastic effects together with shade (Meiss 1991). As a result, there are five main attributes to define the identity of space through light: (i) the way how light enters indoors; (ii) its intensity; (iii) the type of the building elements it falls on; (iv) the properties of the materials used; and finally (v) the shape of all surrounding elements that constitute the space. The identity of the space is determined based on all of these combined qualities of light and space.

\section{Determination of the quality - identity of architectural space by natural light}

The role of light in determining the quality and identity of architectural space can be evaluated in three intertwined dimensions (Table 1). Light can be examined in terms of its effect on the readability of a space and its contribution to the aesthetic evaluation of the space.

\section{Dimension of natural light's contribution to the readability of the space}

Architecture depends on light. Since light, as the element that brings in the third dimension to spaces and objects, reveals the shapes of architecture and the spaces created by these shapes, it also clearly manifests the meanings and purposes in the design idea. Such meanings may be the designer's own and therefore they are subjective.

The first way to give readability to an architectural space, or in other words to explain the thought of the designer to the observer is to strengthen the expression of the boundaries of space. Considering that also light is added on top of this, the result becomes even more original. There are two ways how natural light is used to render the space readable by the designer.
Natural Light as a Tool for Expressing Spatial Elements: In the expression of spatial elements, light underlines, exhibits, and shows the structural set-up of the space, the shapes, colors, and textures of the walls constituting the space. In this way, light is used as an expression tool that strengthens the architectural elements composing the space.

The most suitable example to demonstrate how important light could be in the readability of space is the Pantheon in Rome. Rasmussen (1994) describes Pantheon as follows: "No picture can adequately express it... The circular opening at the top of the dome is the sole relation with the outer world. However, this relation is not established with the daily and noisy world of the alleys but with the sky as a larger dome. When the oblique sun rays do not enter in, the light spreads because it comes from the top. From only one source, they all fall with the same direction, thus creating real shades. The marble floor receives most of the light and reflects in a way to lighten even the darkest corners. In this way, no real black shade occurs in any place. With their Corinthian columns and cornices, wall niches receive enough light to manifest architectural forms with all their plastic effects." (Fig. 3).

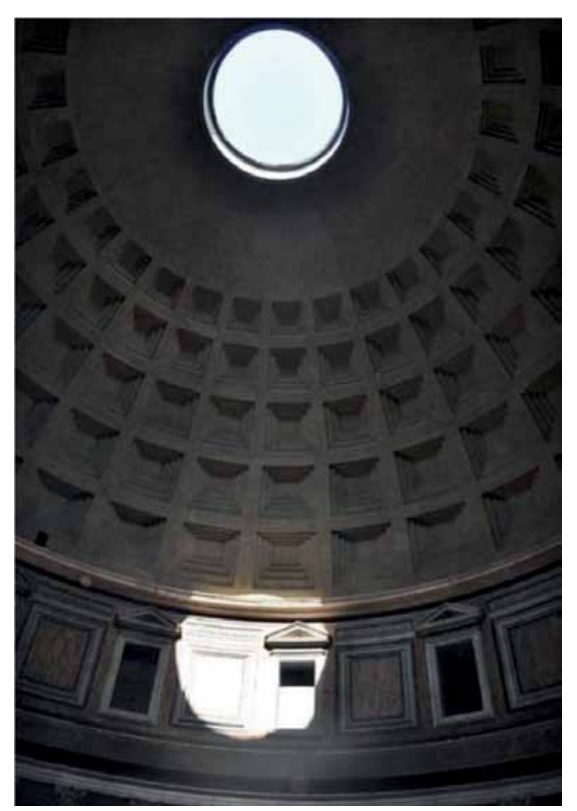

Fig. 3. Pantheon Temple dome

Table 1. Role of natural light in determining the quality - identity of architectural space

$$
\text { Determination of the quality - identity of architectural space by natural light }
$$

\begin{tabular}{|c|c|c|c|}
\hline \multicolumn{2}{|c|}{$\begin{array}{l}\text { Dimension of natural light's contribution to the } \\
\text { readability of the space }\end{array}$} & \multirow{2}{*}{$\begin{array}{c}\text { Dimension of natural light's } \\
\text { contribution to the effect of } \\
\text { the space }\end{array}$} & \multirow{2}{*}{$\begin{array}{l}\text { Dimension of natural light's } \\
\text { contribution to the aesthetical } \\
\text { evaluation of the space }\end{array}$} \\
\hline $\begin{array}{l}\text { Natural light as a tool for } \\
\text { expressing spatial elements }\end{array}$ & $\begin{array}{l}\text { Natural light as a guiding } \\
\text { tool in the space }\end{array}$ & & \\
\hline
\end{tabular}




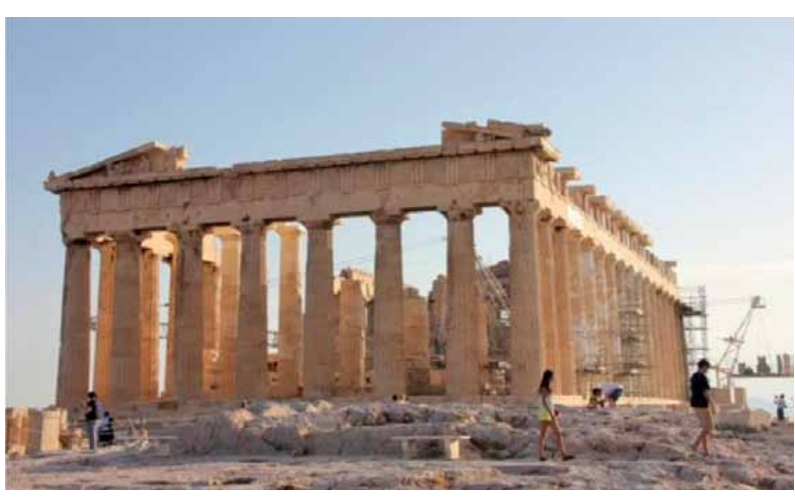

Fig. 4. Parthenon Temple

Use of natural light for rendering space readable in these terms also affects the structure of the space in relation with the way how light is admitted. This relationship between light and the structure brings along the result where light also affects the shape of the space. What draws the limits of the use of natural light within the architectural space and that admits it into the space is not only the building consisting of dividing elements, but also its structure. Allowing light into the space is related with the decisions concerning the construction and structural formation. Since this relationship also affects the external shape of the building mass, the significance of natural light makes is evident at this point.

The relationship between the structural formation and light is emphasized in Kahn's (1968) words on Parthenon: "This space is the start of architecture. This is a space of mind. You are placed in its dimensions, structure, spirituality, light that serves its character and then you understand it was built and given life by humans. The structure of a space has to be the validation of the space itself. According to me, structure is the source of light" Kahn (1968) also said these for the same structure: "In a sense, you can see the notes in the building. If you think that the Temple Parthenon consists of columns and spaces within columns, you may say that the columns are not light yet the spaces in between of columns are indeed light. The columns are the notes, while the spaces between the columns are the rests between notes. These are intervals of light. All along the building the columns offer the rhythm of light, lack of light and light again. And a vault, a dome is the choice of the character of light." (Fig. 4).

Natural Light as a Guiding Tool in the Space: In this kind of readings, light is used by the designer as a tool to guide the user within the space. The perceptional inclinations a person experiencing the space will be put in by the architect and the way how the intended set-up of space will be offered to the observer are important. The transitions between light and dark in an architectural space may be leading based on the perception of the user in the space. Le Corbusier's opinions on the Green Mosque in the Turkish city of Bursa are explanatory of the use of light in this way (Kortan 1983):

"If you enter the Green Mosque in Bursa from a small door at a normal person's height, a quite small entrance hall changes the scale you were used to from the narrow alleys in order to have you admire and be impressed from the space you are in. After that, you feel the noble magnitude of the Mosque and your eyes perceive its size as much as possible. You stand in a space full of light and made of a great white marble. Right ahead, you can see a dimly lit another similar space with broadly same dimensions and elevated with a couple of steps; on both sides there are also smaller spaces with lower light and finally when you turn back, you see two very small spaces in the dark. There is a rhythm, from full light to shade. Small doors and enormous openings... You are speechless; you have just lost your sense of scale! Within the world that is communicated to you, you are charmed by the successful use of an emotional rhythm (light and volume), the scale, and measures. What vigor, what a faith! There are stimulants and objectives that emotionally influence one, and many ideas were used as their tools." (Fig. 5).

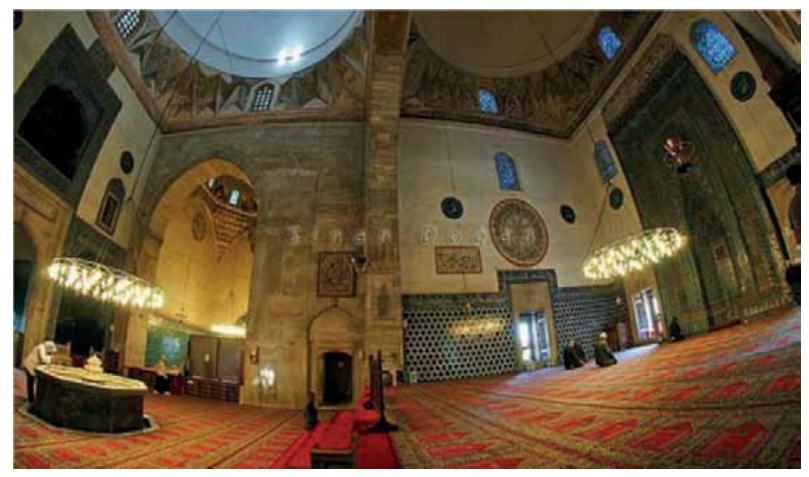

Fig. 5. Bursa Green Mosque. Source: www.bursaport.com

At this point, Corbusier excitedly speaks of spatial hierarchy, scale diversity within the structure of the space, and the obvious effect of light within this formation.

A different view of the contribution of natural light to the readability of the space is related to the minimalist spaces. Minimum use of elements makes it necessary to render the space readable through light. In a study conducted by Irmak (2002), it is also reported that the effect of light and shade can be seen easily in the readability and perception of minimalist spaces. Light and shade enables the space to take shape. By means of light, the materials and details within the 
space manifest themselves with all their simplicity (Irmak 2002). Minimalist architects can achieve the effects, which many designers get by adding and mixing it to the space, through the sole use of a "design tool" such as light.

\section{Dimension of natural light's contribution to the effect of the space}

Architecture is an art, where feelings stir with the impressions one get and thereby it gains a soul. An architectural work that gives the sense of a visual and robust space can be created by the conscious gathering of the elements that bring the user emotional orientations (Aydinli 1993).

As light changes from day to day, from a month to another and from season to season, it also changes the space it enters. In line with the change in time, some differences also occur in the perception of space. Kahn evaluated this as follows: "In today's modern spaces the question of 'how much sun does your building receive?' is pointless. The question should have been: which states of mind does the light bring to you from morning to evening, from one day to another, from season to season and throughout the years?" (Kahn 1974). Frampton emphasizes the psychological aspect of light by saying "Architects often forget that people need a kind of light that provides partial lighting and a sense of quiet" (Frampton 1985). Indeed, it is possible to change the psychological perception of the space without changing its physical form. In this case, the fact that light constantly changes during the day gains further importance.

In architectural space, natural light can also be used to highlight the meanings required by the function carried out in the space. The strongest form of this effect can be seen in religious buildings designed for worship. With the purpose of strengthening the emotion of worship and describe divine powers, the light entering the space from above is generally used as a tool for this. In a study conducted by Aydinli (1993) on the psychological effects of natural light as a set-up element and its effects based on interpretation and observation, the author cited Gropius' view: "It is difficult to imagine the surprise one experiences when the sunlight entering from colored windows slowly creeps on the twilight of the middle section of a cathedral and then instantly hits the mosaic painting or sculpture behind the altar. How exciting for someone observing this!" (Aydinli 1993) (Fig. 6).

The partial lighted and partial shaded state of a space enables it to act on two different tonalities. In this way, the effect of the space changes by means of the plays between light and shade. Since this new status disrupts monotony, it creates a further interesting and

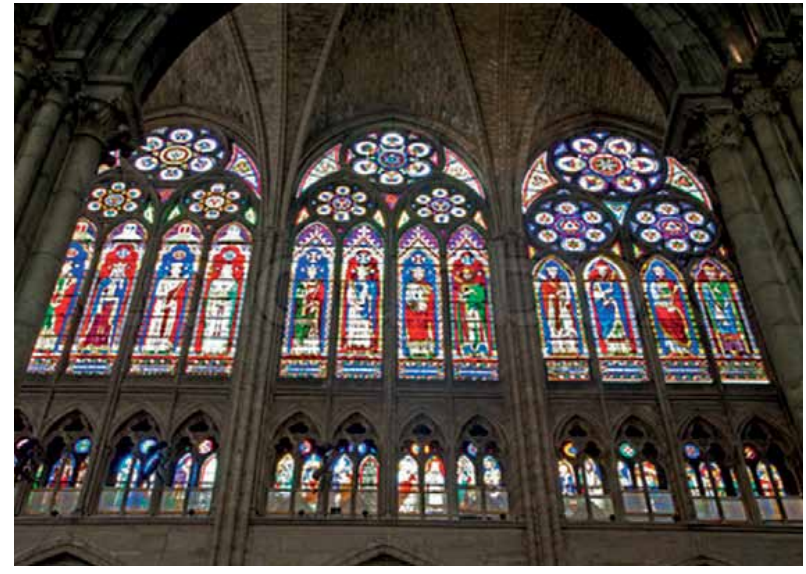

Fig. 6. St. Dennis Cathedral, Paris. Source: www.colourbox.com

plastic appearance. Light can play a significant role in the formation and effect of an architectural space. Beyond the more objective purposes of supporting perception and clarifying the boundaries of a space, light can be the primary factor that renders a space original and that brings in a human identity to it. The way light enters into a space, washes it, gives prominence to certain features, and draws a lighted or dim, gloomy or mysterious character can determine the quality of the room in a decisive manner.

\section{Dimension of natural light's contribution to the aesthetical evaluation of the space}

In an architectural space, the user first receives the signals coming from light and the boundaries of the space. These signals are perceived at sensorial and cognitive levels and result in a certain aesthetic judgment. As an aesthetical object, architectural space is perceived through aesthetical perception. The concept of the space and the semantic dimension of natural light are perceived as a whole in mind. As a result, a certain psychological effect or a meaning of the space transpires as an aesthetic judgment and space consciousness in the user (Yildiz 1995).

A user walking through an architectural space gravitates towards certain feelings through the relationship between the shape of the space, the natural light admitted into it and the volume, and as an aesthetical object the space makes sense for the user.

The dimension that cannot be objectively measured but felt, that is related with feelings and likings defines the aesthetical dimension of natural lighting. This relation applies to both indoor and outdoor spaces.

One of the greatest aesthetical advantages of natural light in architectural space is its variable and non-monotonous nature also mentioned in the previ- 
ous sections above. While the intensity of daylight and the colors it reveals during the day change even within a day, considering the seasonal differences experienced throughout the year, it is possible to realize that natural light embodies an incredible richness in terms of the experiences in the space.

Natural light entering into the architectural space affects the way we perceive and comprehend the space and the meaning and character we attach to it. While experiencing a space, the way we perceive it and our feelings related to it is closely linked with the way light is admitted into the space and the visual effect created through plays of light and shade (Fig. 7). For instance, while a bright and intense light admitted directly into the space would bring in a lively and dynamical expression to the space by creating strong contrasts with shade, an indirect light that is admitted through reflection makes the space rather relaxing and soft through weak contrasts.

The action occurring in the space is an important factor that needs to be considered for having the aesthetic effect created via light to be in harmony with the general characteristics of the space. For instance, while an illumination that draws attention to the objects and that does not strain the eyes is favored in a museum, in religious spaces it is important to create an introvert and calm quality that is different from the normal flow of life. Accordingly, in the evaluation of the aesthetical potential of natural light, it will be necessary to consider the action occurring in the space and to interpret the aesthetic values of the lighting design in a way to integrate those with the function of the building (Dogrusoy 2001) (Fig. 8).

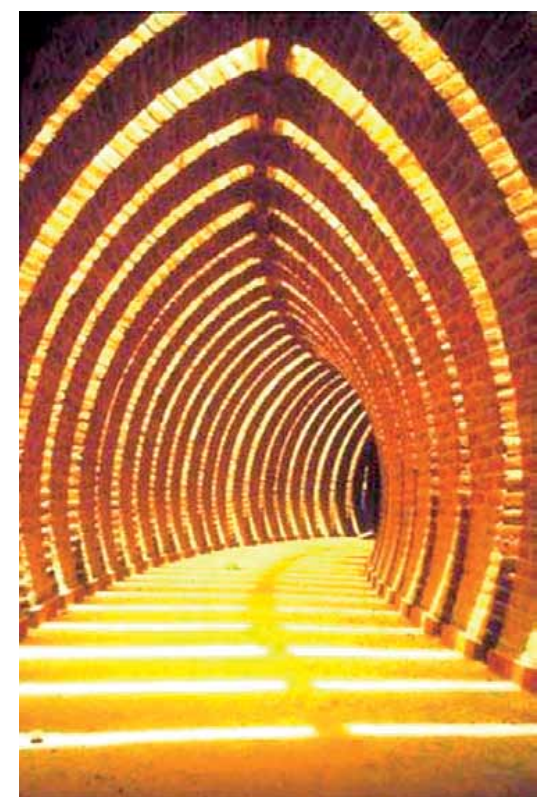

Fig. 7. Kaedi Hospital, Mauritania. Source: www.akdn.org

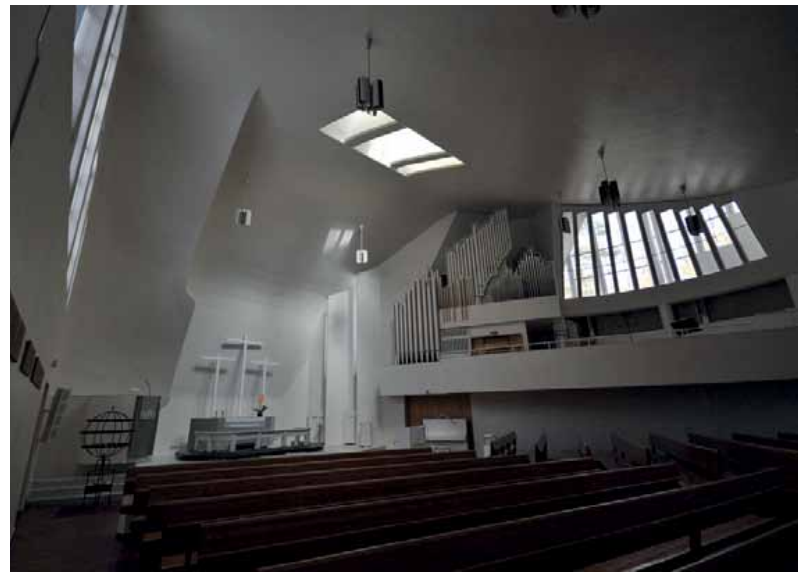

Fig. 8. Vuoksenniska Church, Alvar Aalto. Source: www.flickr.com

Since using and enhancing the aesthetic potential of natural light cannot be based on objective data, it can only happen through experience. However, it is necessary to keep in mind that as in all relationships of natural light with any parameter, also in the aesthetic relation the way how building body takes shape, the proportional and shape characteristics of the openings on the building surface and the colors, texture and material properties of the interiors are important.

Three Architects of Modern Turkish Architecture as Cases to Understand the Role of Natural Light on Determining the Identity of the Architectural Space.

In this section, the aspects of natural light determining the identity of architectural space will be examined through the works of three significant names of Turkish architecture, including Behruz Cinci, Turgut Cansever and Sandor Hadi.

\section{Behruz Cinici}

Behruz Cinici is among the most important names, the creators of the modern Turkish architecture. The works he has been producing for more than 50 years demonstrate his unique design approach. Cinici's architecture exhibits a high level of diversity in terms of shape and materials used. In addition, occasionally one may also find light in Cinici's architecture as an important design element. Among the most significant buildings of Cinici, the G.N.A.T (Grand National Assembly of Turkey) Mosque and M.E.T.U (Middle East Technical University) Faculty of Architecture bears important hints on this.

Having been awarded the "Aga Han Architecture Award" in 1995 due to the innovative approach it brought to the mosque minaret, the G.N.A.T Mosque (Fig. 9) was originally designed as a square, worship 

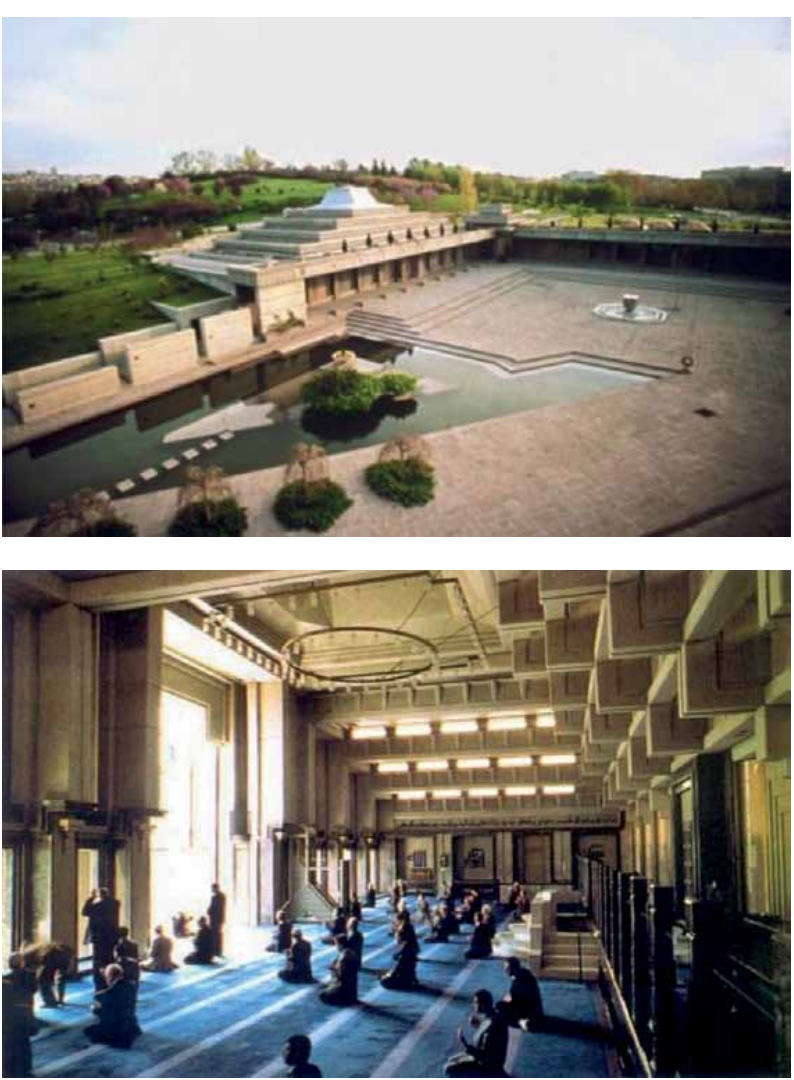

Fig. 9. G.N.A.T Mosque, Ankara. Source: v3.arkitera.com

and library complex. Its mass organization that took shape with a strong yet simple assembly and a humble approach is unique first of all in terms of scale without damaging the characteristics of the context and the assembly building.

Instead of the usual use of a dome, a stepped pyramid that filters light into the building was used. While the minaret was replaced with a double balcony, a cypress tree was used to visually represent the minaret, the qibla wall was made transparent, the mihrab was arranged as a glass niche and visually it was opened to the garden adorned with a cascaded water element. Separation of spaces reserved for men and women on the other hand is expressed only via a difference in elevation. The definition of the forecourt, which is created via embedding, identified with the walls of the mosque and the library, and surrounded by porches, was strengthened with an element of water. An intense light enters the building in front of the mihrab and the "light from above" as the essential element of religious architecture was executed in a way to be filtered through the girders composing the pyramid.

M.E.T.U Faculty of Architecture (Fig. 10) is a building engraved with courtyards positioned on a wide field. By means of these courtyards the building is in-

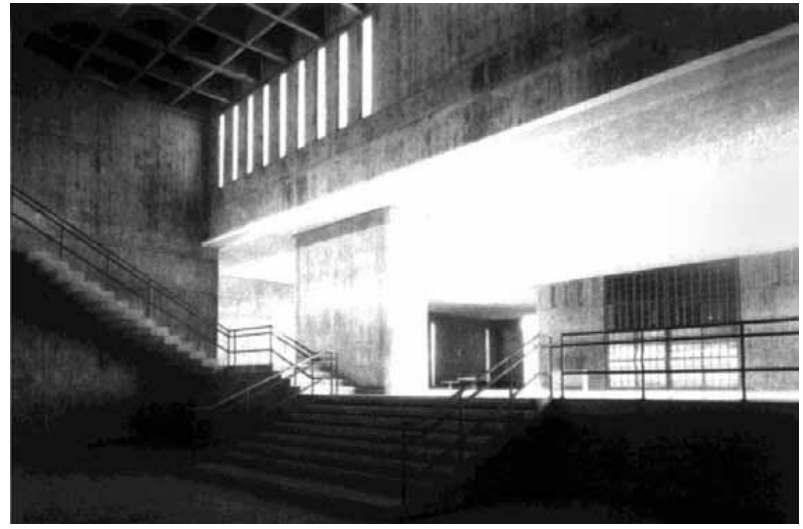

Fig. 10. M.E.T.U Faculty of Architecture, Ankara (Improvisation/Mimarlıkta Doğaçlama ve Behruz Çinici)

tegrated with the green field and light is carried into the depths of the building. Here, light is used as if it is a guiding element. Transitions from dark to light, shades, penumbras, and light entering from above create meaningful thresholds in the holistic and flowing inner halls of the building and determine differentiated sense of spaces.

\section{Turgut Cansever}

Turgut Cansever finds human-oriented architecture that responds to humans' physical, mental and cultural needs essential. Such an architectural understanding brings along the use of light as a design tool. The best example of how light is used as a tool contributing to space identity and quality in Cansever's architecture is probably his most competent work, the Turkish Historical Society building in Ankara.

The Turkish Historical Society Building (Fig. 11) that manifests itself as a reaction against the International Style followed in Ankara since the 1930s, has an architectural language where architectural elements are used in harmony with their traditional forms and where a reinforced concrete framework, andesite from Ankara and polished marble from Marmara create a contrast with aluminum joineries and wooden frames. Particularly with its dark red colored stone walls, outer solid mass and its architectural identity that resembles the formal organization of Ottoman madrasahs, the building is the focal point of its surroundings.

Being awarded the "Aga Han Architecture Award" in 1980, the building is a successful example for the integration of modern building technology with historicist form language. In the building, which has a conference hall, book depots on the ground floor and a library, reading hall and office buildings on the up- 

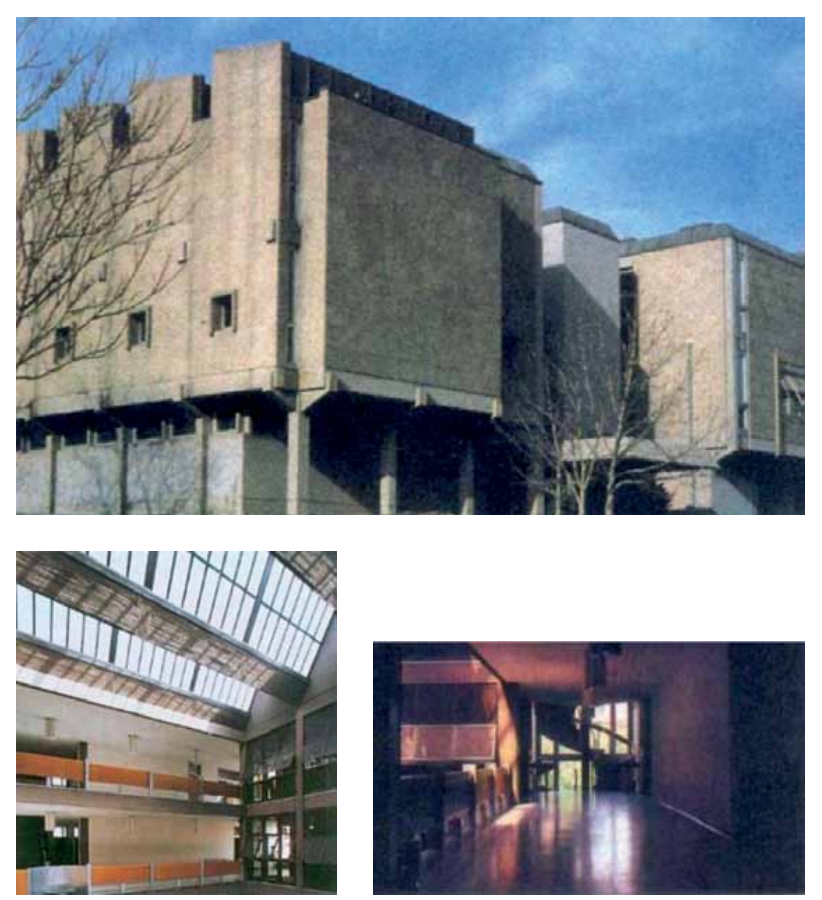

Fig. 11. Turkish Historical Society Building

per floor, the sense of space gathered around a central courtyard reflects the introverted characteristic of Ottoman buildings. The courtyard can also be considered as an extension of the urban space protected against the exterior (Cansever 2001). The space where light is the most effective in the building is this courtyard. In this three storey high courtyard, the light filtered down from the roof exhibits the poetry of the space. Next to this impressing light filling the courtyard, the dimness of the surrounding corridors and the intense light received from the back of the stair enclosure at the end of the corridor give prominence to the stairs as the most dynamic element of the space and guide the user in this way.

Cansever's other work Karatepe Eaves, located in Adana, Kadirli, is a structure in which the remains belonging to late Hittite period are exhibited and preserved. Eaves, built to highlight the doors of the ancient castle and its entrances, were designed by Cansever in 1957 (Fig. 12).

Although it is a semi-open space made of canopies and reinforced concrete columns carrying them, it gives the feeling of being always there while overturning the accustomed concrete-glass-steel memorizes. Here light is a matter emphasized in the design and spatial effects. concerning the projection of the ancient monuments as well as they not to be left in dark, the canopies were arranged to form a well-balanced lightshade relation.
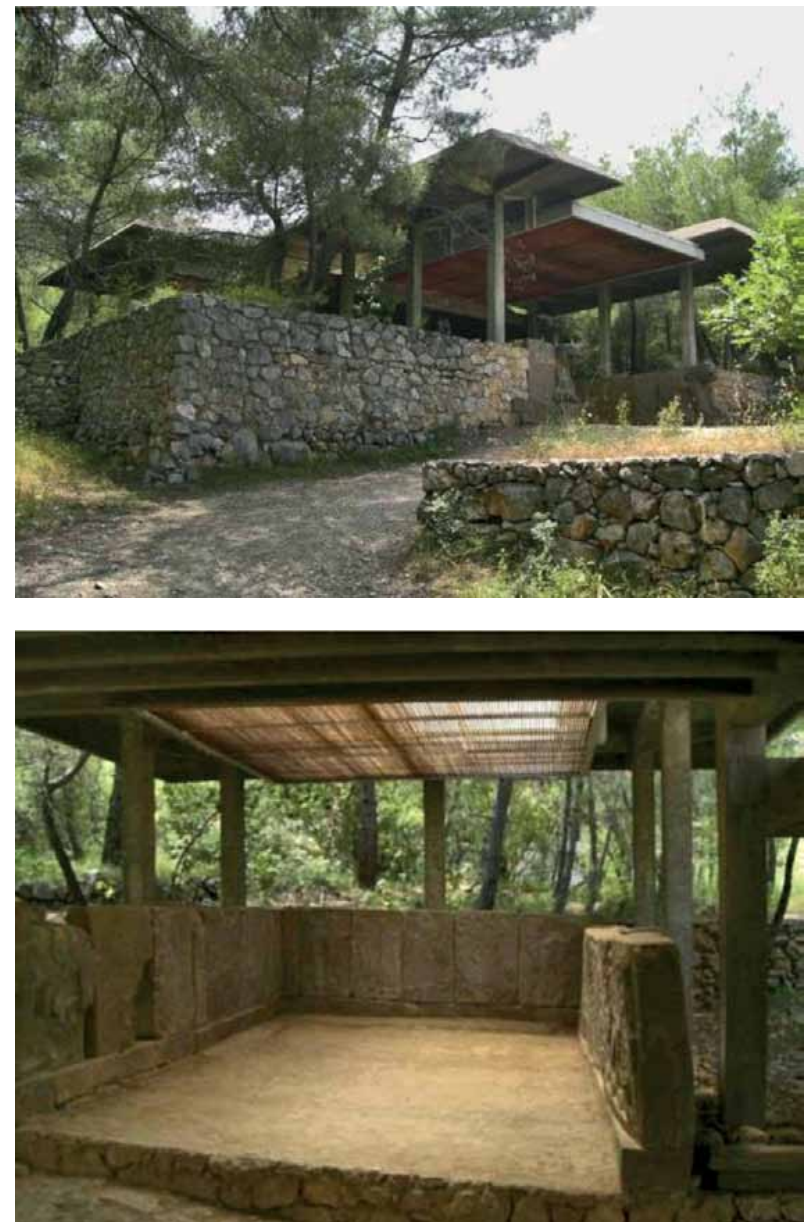

Fig. 12. Karatepe Eaves

\section{Sandor Hadi}

According to Sevinc Hadi, the buildings of Sandor Hadi are the products of an architect who tries to impose peace in users in a simple and plain way without assuming any attitude. Concepts such as revealing the essence of the design, having harmony or contrast, and diversity in textures establish the basis of Hadi's architecture. In his works, Hadi attaches great importance to the hierarchy of the main space and side spaces, and the celestial light reaching these spaces from the sides and the top (Hadi 2002). Although it is considered primarily with its functional aspect, light is also considered in terms of its contribution to the space effect. Beyond this, light may also be one of the most important design elements.

Designed in 1984 and built in 1992, the National Reinsurance Building sets forth the effect of light on shape. The necessity of designing offices distant from the street and therefore from the noise and their need for high amount of light have determined the organization of the form. By means of some vacations and 

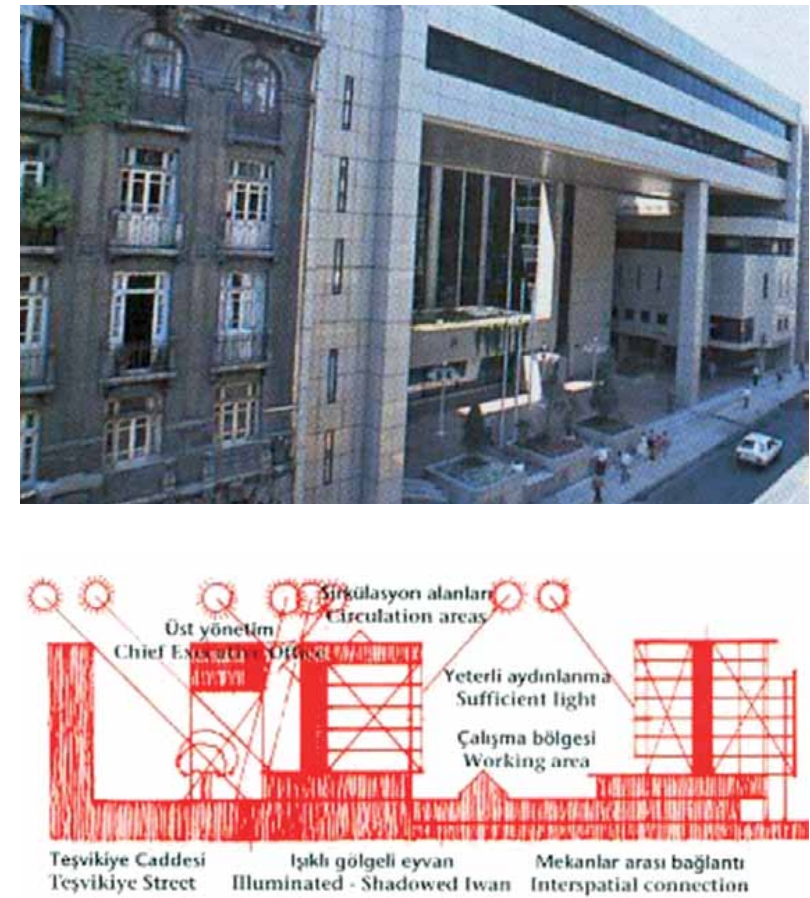

Fig. 13. National Reinsurance Building and its section

withdrawals on the profile, intense light was provided to the offices from the side. In addition, rooftop gardens were established within the building and the desired effect of light was achieved in the interior space (Fig. 13).

Natural light is an important design element also in the Istanbul University and Bogazici University libraries designed by Hadi. Designed within the scope of a contest in 1964, Istanbul University Library was arranged around a present transformer building. Light was admitted into the reading halls designed with the inspiration from the indoors of large mosques from the roof and the side. The light coming through the openings in the roof enters the interior by being reflected from white walls. In this main space that is a whole but felt as if it is divided into three different spaces, light has functional requirements and also a peaceful effect (Fig. 14).

In Cinici's architecture, light is important particularly in giving readability to the space and this is performed with transitions from well-lit areas to dimness by means of the light received from thin slots and courtyards. The language Turgut Cansever created with the Turkish Historical Society building exhibits his view on light. The transition from light-source spaces such as courtyards and stairwells to dim spaces contributes both to the aesthetic and strong spatial effect. As for the architecture of Sandor Hadi, light is given prominence even in the creation of the form. While light affects the
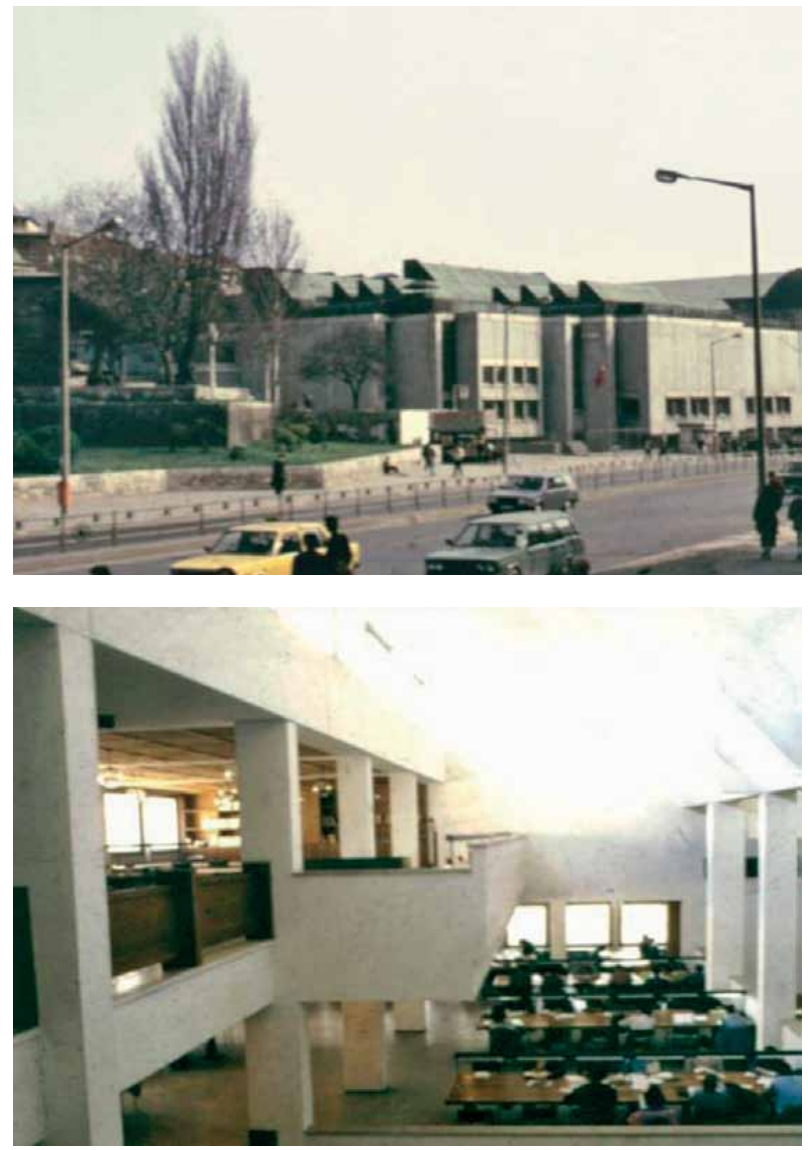

Fig. 14. Istanbul University Library (from Sevinc Hadi's collection)

external form, in the inner space it steps up with the aspect that supports function and also contributes to the general aesthetic (Table 2).

\section{Conclusions}

Throughout the ages, humankind carried out its actions, perceived and existed in a space. Space, beyond its objective and three dimensional physical properties, has turned into a concept with multiple meanings concerned with the subjective aspect of spatial perception. Light is an important factor in spatial perception, since all of the visual effects in a space depend on light. As the quantitative properties of light, such as its type, strength, and intensity change, so does the perception of the space. On the other hand, the qualitative properties of light affect both space perception and space quality. While the quantitative properties of light are provided more easily with controlled artificial lighting, concerning qualitative properties the contributions of both artificial and natural light are important.

However, in contrast with artificial light, natural light is one of the most important design elements that affects the form and meaning of an architectural space. 
Table 2. Dimentions of natural light's contribution to the identity of space

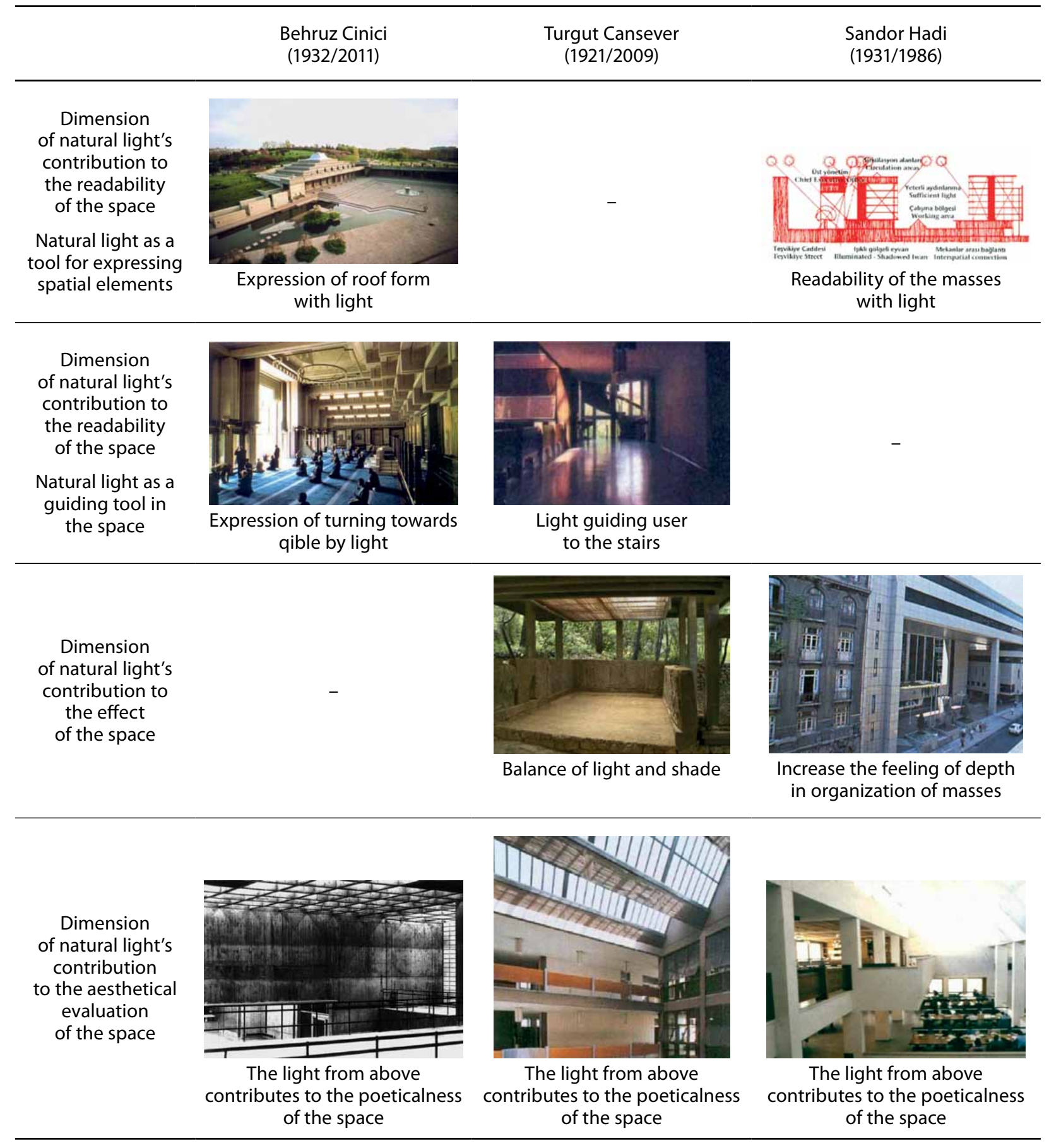

Indeed, after the creation of the architectural space by the designer, the process to perceive and comprehend the space starts for the individual in the space, which now is the object of meaning and expression. Natural light is active in this process and contributes to the readability, effect, and the aesthetical value of the architectural space. For an individual that experiences an architectural space, there is always a subjective dimension in question. With the skills of using natural light within the space, the designer contributes to this subjective evaluation and even guides it in line with his or her own intentions. It is important for the people experiencing the space to have common spatial readings, feel similar effects of the space, and have similar aesthetic judgments concerning the space. This is achieved through these skills of the designer. In addition, with light that enables to shape the soul of the ground, the designer enhances the effect of the space, its poetical nature and readability and the potential of the space to become an actual place. 
Determination of the architectural space identity and spatial qualities by natural light cannot be based on some objective data. Due to this reason, it is possible to state that these aspects of light in a space can only be developed through experience.

The greatest revolutions in architecture took place with the contemplation of the space. Contemplation of space during design, and accordingly consideration of light enables the generation of more unique results. Consideration of light as a part of the space or an important element of design, rather than as an opening on the facade such as a window, may truly result in an extraordinary architecture. In addition, light may also affect the form of the building in a direct manner. Consideration of light as an essential tool in design may result in richness in design such as movement in building form, courtyards, rooftop gardens and light wells. Reasons requiring utilization of light or prevention of too much light may become important concepts in the creation of an original building form.

The form, proportion, and the way how the openings letting light into the space are positioned on the outer facade of the building do not only determine the aesthetic of the internal space but also that of the outer shell. These openings have significant roles in determining the facade characteristics of buildings. It is important to establish a certain balance and rhythm of fullness - emptiness on the facade. Accordingly, in designs where natural light is prominent, the effect of the openings on the aesthetic of the face in the external space should also be considered as well as the functional requirements related to light and concerns regarding the internal aesthetics.

In fact, as also mentioned above using light in architectural space design requires a certain level of conscious knowledge and sensitivity. At the level with which natural light is successfully used as a design tool, such as spatial requirements, ambient data and structural elements of construction, the architectural forms and spaces that come into existence will be more original, more qualified and in this way architecture will continue to create spaces while light continues to give them their identity.

\section{References}

Altan, İ. 1983. Mimaride Ișık Gölge İlişkilerinin Psikolojik Etkileri Üzerine Bir Araştırma. PhD thesis on Architecture. Faculty of Architecture, Yıldız University, İstanbul.

Arnheim, R. 1966. Toward a psychology of art. Berkeley: University of California Press.

Aydinli, S. 1993. Mimarlıkta Estetik Değerler. PhD thesis on Architecture, Faculty of Architecture, İTÜ, İstanbul.
Cansever, T. 2001. Türk Tarih Kurumu Binası. İstanbul: Boyut Publications.

Dogrusoy, İ. T. 2001. Doğal Aydınlatmanın İşlevsel ve Estetik Boyutları, Yapi, no: 235. İstanbul.

Frampton, K. 1985. Louis Kahn, Rassegna, vol. 21, Mart, 268.

Fueg, F. 1980. Mimarinin Temelleri, IDGS Akademisi tarafından 11-14 Kasım 1980'de düzenlenen "Mimari Nedir?" seminerine sunulan bildiri [Paper presentation at IDGSA "What is Architecture" seminar, 11 - 14 November, 1980].

Hadi, S. 2002. Personal interview, 4 January, 2002.

Irmak, H. 2002. Mimarlıta Yalınlık ve Minimalist Tavır. Master thesis on Architecture. Faculty of Architecture, İTÜ, İstanbul.

Kahn, L. I. 1968. Architecture: Silence and Light, Conference at Guggenheim Museum, 3 December, 1968. Brownlee, D. B. (1991), 127 p.

Kahn, L. I. 1974. Credo, Architectural Design, 5, 280.

Kortan, E. 1983. Le Corbusier Gözüyle Türk Mimarlık ve Şehirciliği. METU, Ankara.

Meiss, V. 1991. Elements of Architecture, from Form to Place. Van Nostrand, Reinhold International.

Plummer, H. 2012. The Architecture of Natural Light. London: Thames and Hudson.

Rasmussen, S. E. 1994. Yaşanan Mimari, Çev: Ö. Erduran. Remzi, Kitabevi, İstanbul.

Read, H. 1974. Sanatın Anlamı, translated by Güner İnal, Nuşin Asgari. No 87, İst., Türkiye İş Bankası Publications. 38 p.

Roth, L. M. 2000. Mimarlı̆̆ın Öyküsü. İstanbul: Kabalc1 Publications.

Schulz, C. N. 1980. Meaning in Western Architecture. London: Studio Vista.

Tanizaki, J. 2001. In Praise of Shadows, translated by T. J. Harper, E. G. Seidensticker. Vintage.

Yildiz, G. 1995. Doğal Işı̆̆ın Mimari Mekanı Biçinlendirmesi ve Anlam Boyutu Üzerine. Master thesis on Architecture. Faculty of Architecture, İTÜ, İstanbul.

\section{ILKER FATIH OZORHON}

Department of Architecture, Faculty of Architecture and Design, Ozyegin University, Istanbul, Turkey.

E-mail: ilker.ozorhon@ozyegin.edu.tr

Dr İlker Fatih Özorhon graduated from Yıldız Technical University, Faculty of Architecture in 2000. He got the master degree from Istanbul Technical University by his thesis on "Natural Light with Its Aspect Determining the Identity of Architectural Space" at Architectural Design Program in 2002. He completed his PhD studies at Istanbul Technical University, Architectural Design Program by his thesis named "The Issue of Originality in Architecture: Turkish Modernity in the period of 1950-1960" in 2008. He has studies published in several journals, presented in symposiums and congress and has awards in architectural design competitions. He is working as an Assistant Professor at the Faculty of Architecture and Design in Ozyegin University. His recent research areas include Architectural Design, Design Teaching, Modernity and Modern Architecture, Modern Turkish Architecture. 


\section{TURKAN ULUSU URAZ}

Department of Architecture, Faculty of Architecture, Eastern Mediterranean University, Cyprus.

Dr Türkan Ulusu Uraz graduated from Karadeniz Technical University, Faculty of Civil Engineering and Architecture. She got the master degree from Catholic University of Leuven. She completed her PhD studies at Karadeniz Technical University, Graduate School of Natural and Applied Sciences. She is working as an Associate Professor at the Faculty of Architecture in Eastern Mediterranean University. Her research areas include Theory and Methods of Architectural Design, Philosophy of Architecture and Design, Psychology of Design, Design Teaching, New Design in an Old Setting, Traditional Dwellings, Early Modern Architecture-Modern House, Theories of Architecture and Design, Modernity and Modern Architecture and Housing and Gender Issues. 